Local voices, 'talkback', and commercial regional FM radio

Kate Ames

Lecturer, Professional Communication, MPRIA

School of Contemporary Communication

The Faculty of Arts, Humanities and Education

Central Queensland University

Building 353

City Campus

Rockhampton QLD 4702

Ph: 0749232517

Fax: 0749210441

k.ames@cqu.edu.au 


\title{
Local voices, 'talkback', and commercial regional FM radio
}

\begin{abstract}
Commercial FM stations in Rockhampton, Sea FM and Hot FM, have been operating in the city since late 2000 . Previously owned by competing networks (Sea FM by RG Capital Radio and Hot FM by DMG), they are both now owned by Macquarie Regional Radioworks. The push for listeners has always been through the station's breakfast programs.Traditionally, commercial FM breakfast slots have been marked by comedy of humour-oriented teams. Interaction with these teams in a metropolitan environment has not been studied academically, but studies of interaction between listeners and presenters of breakfast programs in the Rockhampton and Gladstone region reveal that talkback in a traditional sense has emerged as a vital component of the program, at times focusing on serious local issues.
\end{abstract}

This paper reveals the results of analysis of interaction between listeners and breakfast presenters on Hot FM and Sea FM. It reveals that the commercial FM stations provide an important opportunity for locals to voice their opinions on local issues in a format generally renowned for its light-hearted approach to engaging listeners. Where previously 'talkback' has been associated with $\mathrm{ABC}$ and commercial AM stations, this paper will consider definitions of talkback in terms of their application in a regional setting, and reveals the popularity of the format for a demographic previously ignored in the Central Queensland media landscape. 


\section{Introduction}

"We're not here to be political...we're here to be ridiculous."

Jess, of 'Will and Jess', Hot FM Central Queensland

As changes to media ownership laws once again raise the question of the impact of aggregation and concentration on media services to regional Australia, it is timely to specifically examine the content of regional radio amidst arguments about locality, relevance, and radio's impact on regional communities. This issue provides a great opportunity to examine how 'matters of local significance', as discussed in the Broadcasting Services Act 1992, are actually raised in a regional environment. While regional radio is subject to academic discussion in the context of media ownership, there has been only limited research into the content of regional radio in Australia. Talkback radio has not yet been examined in rural and regional Australia, and specific studies of content in other radio genres appear to have been limited to government reviews as opposed to independent academic research.

This paper attempts to fill this gap somewhat by examining local content on two commercial FM breakfast programs. It is these types of programs that have been subject to increasing levels of networking as commercial stations struggle to retain viability. While music content on radio is regulated, the talk component is not. This paper will examine the talk component of these programs, arguing that it plays an important role in community building, and has parallels with traditional talkback radio in allowing local 
voices to be heard.

\section{Defining 'Talk'}

Talkback radio is rarely specifically defined, despite increasing attention being paid to the genre both in Australia and the US/UK in recent times. In Australia, much of the attention paid to talkback radio has been in relation to the genre's role within the public and media sphere (Flew 2000; Turner 2000), while in the US and UK, attention has been paid to specific shows as the subject of conversation analysis by discourse analysts (Brand \& Scannell 1991; Fitzgerald \& Housley 2002; Hutchby 1991, 1996; O’Sullivan 2005; Rendle-Short 2005). Ciccotelli et al (2005) argue that while commercial talkback is generally the subject of research, the range of talkback in Australia is diverse, but in saying so, no definition of talkback is provided. Turner (2000) comes closest to providing a definition in an Australian context when discussing AM commercial stations' reliance on talkback programming as an alternative to music: "Talk radio in commercial terms is now almost exclusively 'talkback' or what the British refer to as 'call-in"” (251). In New Zealand, Morris Shanahan refers to 'talk-based' programming, which leaves little ambiguity and may ultimately be a preferred term (Shanahan \& Brown 2002).

That said, there are common elements of talkback radio that can be identified as being fundamental to the genre. Talkback radio provides the opportunity for public members to voice their opinions on air and thus plays an important role within the public sphere (Griffen-Foley 2004; Turner in O'Regan 2003). Its interaction is subject to production 'interference', although research suggests that callers are very aware of this and understand that this is part of the genre (Hutchby 1996; O'Sullivan 2005). It has been 
argued that talkback radio relies on the popularity/personality of the host (Appleton 1999; Lewis 1992; Osborne \& Lewis 2001; Turner 2000), and encourages a populist approach to debate (Flew 2000; Mickler 1997; Page \& Tannenbaum 1996; Ward 2002). Finally, talkback radio takes place at a point of potential friction between commercial imperatives - that is, entertainment values-- and social responsibility (see Flew 2000; Mickler 1997; Turner 2000, 2001). In the literature, talkback radio is overwhelmingly dealt with in relation to a 'talkback program', identified with a specific host, and dedicated to discussion of issues, be they local, political, or just general views. Researchers refer to talkback in different ways - talk-in, call-in or phone-in interaction (UK), talk radio (US), and talkback (Australia) - but overwhelmingly refer to it as different versions of the same beast: personality-driven, and issues-based.

In all its forms, talkback is rarely ever discussed in the context of being an integral part of programming on popular music programs. Wayne Mac in Don't Touch That Dial (2005), however, notes that while separate talkback shows were established on the commercial AM stations in Australia as soon as the Broadcasting Act in 1967 made it possible to broadcast live phone calls to air, some music oriented programs also made use of the ability to interact with their listeners in this way. Mac notes that even John Laws started his 'talkback' career as a DJ, where he "took time out from the music to speak with callers live to air” (2005: 76). In Laws' own words: “...the talkback element certainly didn't get in the way of the music as far as I was concerned" (quoted in Mac 2005: 76). Mac also notes that music stations recognised the potential of 'talkback technology' (ie. telephones) through requests, contests, and interviewing guests (2005:77). Talkback and 
commercial music programs have, therefore, had a relationship since the introduction of talkback radio, but it is one that has not been studied previously in either metropolitan or regional contexts in Australia.

\section{Talkback in Central Queensland}

Rockhampton and Gladstone in Central Queensland are regional cities that lie 100 kilometres apart. While they are demographically quite different (Rockhampton has an agricultural history while Gladstone's background is firmly industrial), both cities are currently benefiting from a mining boom that has seen an influx of workers, low levels of unemployment, and rising housing and rental prices. This in turn has seen increasing pressure on the infrastructure and management of both cities. Local citizens, therefore, have had a lot to talk about.

The area is quite well serviced by media due to the location of Rockhampton as being almost the half-way point along the Queensland coast. WIN television is based in the Rockhampton and also covers Gladstone. The local papers, The Morning Bulletin (Rockhampton) and The Gladstone Observer (Gladstone), both APN, have been published for over a century, and the local ABC Capricornia was one of the original ABC radio stations established in 1932. Two commercial AM stations have been present since the 1930s (4RO and 4CC - now both owned by Prime Television). Triple J was introduced in 1996, and the two commercial FM stations Sea FM and Hot FM (Macquarie Regional Radioworks) --the focus of this paper-- were established in 2001. 
There are free community papers (also APN), and four community radio stations (4YOU, 4NAG, 4US, and RHEMA) in the area.

In terms of talkback, Rockhampton and Gladstone residents have a number of options when wanting to listen to talkback radio, and thus air their views on local issues. Jeff Goodwin's 'Talk of the Town' on 4RO (Rockhampton) is the most notable, and runs between 5 and 9 am weekdays. Goodwin is currently nominated for 2006 Best Talk Presenter alongside such notable metropolitan counterparts as Steve Price (2UE), Stan Zamanek (2UE), Bob Francis (Fiveaa) and Neil Mitchell (3AW). Goodwin's program is very much talk-based, and features interviews with local community members, politicians, plus the invited calls from listeners. 'Talk of the Town' topics are often featured in The Morning Bulletin, and its focus tends to be Rockhampton-oriented, although at times it does cover Gladstone issues. The show is immediately followed by the John Laws program, beaming in from 2UE Sydney.

$\mathrm{ABC}$ Capricornia also invites listeners to call in to numerous programs throughout the day. The Morning Show (currently Jacqui Mackay, but normally hosted by Craig Zonca, $8.30-10.30)$ is a locally based program, and asks listeners to call in on a range of local and lifestyle oriented topics. Queensland Drive, which is broadcast live from Rockhampton between $2-4$ pm weekday afternoons and is hosted by Ingrid Just, features lifestyle topics and invites talk on these issues. Local Central Queensland issues are rarely addressed because the program is networked from Rockhampton to nonmetropolitan Queensland locations. Local radio listeners, therefore, have two main 
opportunities to air their views through interaction with radio hosts - ABC Capricornia's morning program, and Jeff Goodwin's 'Talk of the Town'. The demographics of these stations, however, privilege the traditional audience of talkback ('mature') so two other options on the commercial FM band have emerged as alternatives for local listeners to air their views on local issues. These two stations constitute a significant departure from the traditional profile of talkback radio in Australia.

Macquarie Regional Radiowork's commercial music-based stations Sea FM and Hot FM are now well-established in the cities, and after a relatively turbulent five years ${ }^{\mathrm{i}}$, have settled into a familiar and popular pattern with their under 40s audiences. Sea FM is Rockhampton-based, and aims for a 20s/30s demographic, and Hot FM is Gladstonebased, and aims for a teens/20s demographic. While the two stations are based in two different cities, they have the same broadcast area, and their home bases are mostly quite 'silent'. ii Both have a breakfast presenting team - Sea FM has two males, and Hot FM has a male/female team. While there have been changes since, this paper is based on a period of taping during mid 2006: Sea FM's team was Smithy and Blunty, and Smithy and Chooky (after Blunty left to move on to Canberra). Will and Jess have been the regular breakfast presenting team on Hot FM since early 2006.

As discussed earlier, within the Australian radio research literature, there has been no consideration of interaction between presenters and audience members who call in and discuss local issues on music oriented shows. There has been, however, is an increasing degree of networking of these types of programs from metropolitan hubs into regional 
areas, and it is important to consider the role such programs play in providing a local voice, even if that voice is quite different to that expressed via traditional forms of talkback. If the programs provide the opportunity for the public to voice their opinions on air, if the interaction is subject to production interference, the programs rely on the popularity/personality of the hosts, populism is reflected in discussion, and the nature of the talk embraces the potential friction between commercial imperatives and social responsibility, then we could actually suggest that the format is in these respects similar to traditional talkback.

In defining what social or cultural role this form of talkback plays, localism is also a key issue. The Federation of Australian Radio Broadcasters (FARB) has previously argued that localism 'doesn't have to be someone in the studio in the town to which the program is being broadcast. It is about what comes out of the speakers from the consumers' perspective - it is material of relevance and appeal to the local audience' (2001). The next section will analyse talk interaction motivated by a desire for ratings on commercial FM stations in Central Queensland, and provide evidence that material of relevance and appeal to the local audience is, contrary to the FARBS position, directly linked to those in the studio or town in which the program is being broadcast.

\section{Categorising radio talk}

Barnard (2000) argues that there are five principal forms of radio speech: the reading of news; narration from a script, commentary on events; conversation or interview; and adlibbed, spontaneous speech (2000: 176). Breakfast programs involve significant 
interaction with listeners through a variety of methods, but much of the interaction between presenters, and between presenters and their audience is 'conversation' or 'adlibbed, spontaneous speech' (Barnard 2000: 176). Breaking this down further, Jefferson and Lee (1994) suggest that there are three types of calls made by listeners into a station: service encounter, expressive and troubles-telling calls. Service encounter calls are problem solving calls, which are short, and "talking is a means to a non-verbal end" (O'Sullivan 2005: 721). Expressive calls are signified by a caller expressing views or trying to get their point across (see O'Sullivan 2005), and troubles-telling calls are where "the focal object is on the teller and his [sic] experiences" (Jefferson \& Lee 1981: 411).

Content analysis is a quantifiable methodology that provides base-line figures and boundaries for this study. While the frames used for analysis are based on an interpretive approach, actually counting instances of interaction provides some guide for more qualitative analysis. Building on the typologies drawn from Barnard's conversation, and ad-libbed, spontaneous speech, and Jefferson and Lee's orientations of service encounter (SE), expressive calls (EC), and troubles-telling (TT), the research conducted for this project placed the interaction between presenters and listeners on the breakfast show programs into four basic categories:

1. Competition (SE) - The listener has phoned in as a response to a competition in an attempt to win something.

2. Storytelling (EC/TT) - The listener has phoned in to tell a story about themselves, or give an opinion that is not related to a competition. 
3. Promotion (SE) - A member of a local company/business (for-profit) is in the studio with announcers and fielding calls, or is on the phone indirectly or directly promoting their organization.

4. Community (SE) - A member of a non-profit organisation is on air with announcers and fielding calls.

These categories emerged during the course of my doctoral study, and were defined in the course of studying commercial station breakfast programs. We will return to them a little later in the analysis, after some contextualising of the specifics of the formats in the programs under consideration.

There are two main elements of talk within the Sea FM and Hot FM format. These are talk amongst the presenters, and talk between the presenters and listeners. As is standard practice on talk-based and current affairs talkback programs, the presenters on Sea FM and Hot FM read newspapers, and discuss topics of the day, generally based on a story or issue that presents itself. However, in their effort to be 'ridiculous', as put by Jess, the topics that were set to invite audience participation were much lighter in tone. Despite there being a seemingly distinct divide between the authority of the presenters to comment on serious issues, balanced with the apparent desire to keep the session light and happy ${ }^{\mathrm{iii}}$, there were actually three categories of talkback that appeared evident: the light ('ridiculous'), the topical, and the community building.

In terms of 'light' sessions, talkback topics were diverse. As occurs on more traditional talkback programs, talkback topics in this case were often initiated by stories in 
newspapers, but were sometimes also based on the personal experience of the presenter. Topics during the taping period included (as examples): 'If you get overcharged at the supermarket, should you go back?' (Hot FM, 17 May, five calls); 'Do you have toilet issues?' (Hot FM, 22 May, two calls), 'Have you ever lied on your resumé?' (Sea FM, 1 June, two calls); 'What's the strangest place you've fallen asleep?' (Sea FM, 18 May, no calls); 'What's the coldest place you've ever been?' (Hot FM, 1 June, four callers), and 'Should it be cash or gift at a wedding?' (24 May, Hot FM, seven calls).

In addition to these, there were instances where both Sea FM and Hot FM attempted to engage local listeners on topical issues. For example, after the Tracy Grimshaw interview with the survivors of the Beaconsfield mine disaster, both stations ran talkback sessions on the interview. Hot FM asked 'Were the Beaconsfield miners paid too much?' (22 May, three calls), while Sea FM simply asked 'What did you think about the Great Escape interview?' (22 May, two calls). Another topical subject included 'What do you think about the differences in crime between Rockhampton and Gladstone?' (Sea FM, 17 May, five calls) after the local papers The Gladstone Observer and The Morning Bulletin had waged a front page war about differences in crime between the two cities.

Although both stations addressed the Beaconsfield mine disaster, the approaches were very different. Sea FM hosts sympathised with the miners, saying they deserved everything they got in terms of money. The hosts ask listeners to call in to tell them what they thought, prefacing this with, "Yes, very moving stuff". Hot FM hosts on the other 
hand use an excerpt for comedic purposes, albeit one that is based on a firm social point (family should come first):

Will: Some interesting perspectives coming out from the interview. Todd had, er, .hhh a changed perspective on life...

Todd: It changed my perspective on life. There were a lot of times where I would get up and go kangaroo shootin' rather than have a family photo done, where now I see it, shootin' comes second now, my family comes first.

[Laughter from Will]

Jess: O::h, I'm glad he's had such a positive change of heart [sarcastic tone...changes to strine accent]...Fîrst comes me piggin' dogs, then comes me shootin', then comes the kids, then comes the missus... [back to normal voice]. Did you, did you hear how he referred to her the whole night as the wife? $>$ THE WIFE $<$ ?

Will: Well they're in love. Todd will be up for Australian Dad of the year, what, because "I put my shooting second now".

Jess: I'(h)ve got the family comin' first. Dead set.

Will: There were some insights...

The conversation continues, and Will and Jess reveal the amount of money paid by Channel 9 for the interview. They express their opinion, saying that considering the amount of advertising revenue they would be receiving, the price paid was not enough. They then go on to ask listeners whether they thought the interview was value for money. 
Smithy and Blunty (Sea FM) simply ask listeners to ring in and talk about what they thought about the interview after also playing an excerpt about how hard the experience had been. In neither case was the response overwhelming, with only two and three calls being made into the stations on the topic.

Finally, the third category of talkback topics was in relation to community building. The reason it is defined as such is due to the fact that listeners were asked to call in to be part of a 'bigger picture' local issue. There were two major examples over the period of study, and these were overwhelmingly the most popular in terms of listener participation. The first was in relation to Will (Hot FM) who was due to celebrate his $30^{\text {th }}$ birthday at the end of June. Jess, Will's counterpart, invited listeners to call in to suggest things that Will needed to do before he was 30 . The response was overwhelming, with listeners phoning in each day in early June to suggest an activity, ranging from a full body wax, tattoo, to eating bull's testicles (all challenges which were subsequently taken up by Will on radio). A total of nine callers to the first request for ideas was the biggest single topic response during the period of taping. The second community building topic was in relation to Sea FM's 'Give me Five for Kids'. This is an initiative run by the station that raises money for the paediatric units at the local Rockhampton and Gladstone hospitals. A request from Smithy and Chooky to 'call in and let us know if you want to help' again elicited the single biggest response in relation to topics during the period of taping (eight callers). In the case of 'Give me Five for Kids', some of the calls were from local small business owners who were prepared to donate equipment for auction, money, and services. 
Thus, direct requests in relation to community building appeared to be the most successful strategies used by presenters in promoting talkback on the station's morning programs. Local listeners were in some way able to negotiate with the agenda of topics. Interestingly, given conventional criticisms of the content of talkback, the 'lighter' the subject, in many cases, the lower the response, and in some cases there were no calls at all. It became quite apparent that local listeners were more interested in engaging on topics where they had something specific to contribute, and were interested in local community building activities. At the same time, when it came to interaction between presenters and listeners, there was not a lot of time set aside for the calls, and interaction was often as basic as getting a response, and moving on. There was little elaboration, or prompting of elaboration, from the presenters.

A point of difference from traditional politically oriented talkback is that topics for talk were overwhelmingly about personal experience, as opposed to personal or political opinion. Topics were not based around 'what do you think?'; rather, the focus was on 'what have you done?'. In returning to talk categorisation, the majority of the calls in the context of commercial breakfast programming talkback were Service Encounter (problem solving - provided in advice, or answer to question), or Troubles Telling (focus on experience). Expressive Calls (put forward an opinion) were rare, as the nature of the talkback topics did not overly encourage this approach to interaction.

Interestingly, there appeared to be a deliberate intent of the stations to not engage in politically oriented discussion. For example, on 30 May, talk within the city of 
Rockhampton turned to migrant workers in Rockhampton, a topical issue due to the importation of foreign workers within the meatworking plants. On that date, Sea FM's Seacruising Sara based her vehicle amongst a group of protesters who had been staging a roadside protest against the importation of foreign workers by Teys Brothers, who owned a local meatworking plant. A few days later, on 1 June, Rockhampton became the focus of the national current affair spotlight when current affairs program A Current Affair travelled to the city to talk to the group. The following day, when Sea FM discussed the topic of foreign workers, the topic for the day was 'what have you been up to while your parents have been away?'. There was no engagement of the topic at all on Hot FM.

Despite this point, the key question is whether or not Sea FM and Hot FM provide talkback as part of their regular programming, and if so, does it provide an opportunity for local listeners to engage with local topics and a wider listening community? There is no doubt that the answer is yes. The question that follows from this, however, is whether the topic 'Do you have toilet issues' is as important for community building as a political topic on the John Laws talkback program?

Here, we return to FARB's argument that to be relevant to local listeners a program does not necessarily have to be local, and to the Broadcasting Act's notion of 'matters of local significance'. It is easy to dismiss the talk-based banter on commercial breakfast radio programming as trivial and unimportant. It is also certainly true that a program can be relevant to an audience without being local. The data in this case, however, reveals that what could be considered apparently trivial is actually part of an audience engagement 
process that has important ramifications for 'what it is to be local'. Here, the audience has determined what the matters of local significance are for them. In the case of Sea FM and Hot FM, the audience has elected to move to these stations from previous alternatives (in 2000 , the music oriented choices in the region were $4 \mathrm{CC}$, 4RO or Triple J which had over $30 \%$ of the demographic audience). 'Localness' has been how the stations have promoted and defined themselves, and it is apparent that listeners have responded very favourably to this. In this case, the programs rely on the fact that they are produced in the local area, and are more relevant to an audience because they are local; in fact, they would not work in the same way if they were not.

This study also highlights the potential to link the talkback format a younger generation than is traditionally associated with talkback programs. According to Mac, and many of those he interviewed, talkback belongs to an aging generation: "We're now considered an aging society and people tend to gravitate to talk radio, as younger people do with music radio and other entertainment sources' (2005: 82). In the case of Sea FM and Hot FM, talkback opportunities are introduced to a demographic that otherwise would have limited opportunity in mainstream media to voice their views on local issues. The competition for listeners has encouraged stations to engage with their listeners at prime listening times in other ways, and as noted, the talkback format has emerged as a successful way of engaging local listeners.

It is, therefore, very evident that there is a real attempt to include talkback in breakfast show programming, but at the same time these regional commercial stations are 
deliberately not trying to emulate political or current affairs oriented counterparts. This paper has, however, attempted to highlight the similarities between this genre of radio and that which is traditionally associated with talkback programming in Australia. It highlights the potential of local regional commercial radio to engage local listeners on a range of topics. While there is no doubt that the approach to topics is quite different from traditional talkback options in the local area and beyond, listeners are keen to share personal experiences and engage in community building, thus supporting the notion that to be relevant in a regional context, there is a strong case for the station to be local. In an isolated regional environment where there is limited choice for alternative media choice, it is important not to disregard what may be seen as 'trivial banter' when the evidence shows that within the format, there is room for significant community engagement. Questions of value in relation to the topics discussed are, perhaps, for another discussion.

\footnotetext{
${ }^{\text {i }}$ Sea FM was initially owned by RG Capital Radio (sister AM station was Rockhamptonbased 4RO), and Hot FM was owned by DMG (sister station was Gladstone-based 4CC). Both Sea FM and Hot FM were based in Rockhampton and competed heavily with one another for 'who is the most local'. In 2005, Macquarie Regional Radioworks bought all four stations, and was required to sell off two within a year. It retained the two commercial stations, relocating Hot FM to a Gladstone base, and retaining Sea FM in Rockhampton. Over the past five years, there have been significant changes in presenter mix and programming orientation. This has currently stabilised with consolidation of ownership.

ii The two stations, plus Triple J, have been the objects of study over a long period (Triple J since 1996, and Sea FM/Hot FM since 2001), and are currently the subjects of my PhD thesis that seeks to identify how notions of community and identity are revealed during interaction between presenters and local listeners. This paper is based on data collected for analysis that involved taping of breakfast programs over a four week block in May/June 2006. Taping was only on weekdays (7.15 to $8.45 \mathrm{am}$ ) due to the fluctuating nature of weekend broadcasting, and provided approximately 30 hours per radio program for analysis. This time period was selected because it was limited to 90 minute taping sessions based on technology available to the researcher.
} 


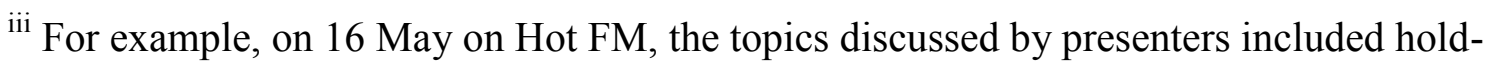
ups in the local area, and a visit by a professor of health to local children in Gladstone. The talkback for the day was on 'what movies have you walked out on' (resulting in four calls).

\section{References}

Barnard, S., 2000, Studying Radio, Oxford University Press, London.

Brand, G., and Scannell, P., 1991, 'Talk, Identity and Performance: The Tony Blackburn Show' in (ed) P. Scannell, Broadcast Talk, Sage Publications, London, pp. 201226.

Ciccotelli, C., Gorham, A., Hill, D., and Pham, T., 2005, 'Yakety Tak, Let’s Talkback: Talkback Radio Across Australia', research paper for COMU3000 Research Methods, University of Queensland, Brisbane.

Appleton, G., 1999, 'The Lure of Laws: An Analysis of the Audience Appeal of the John Laws Program', Media International Australia incorporating Culture and Policy, no. 91 , pp. $67-81$.

Douglas, S., 2000, ‘Talk Radio: Letting Boys Be Boys', El Dorado Sun, 27 June, URL http://www.alternet.org/story.html?StoryID=9368

Federation of Australian Broadcasters, 2001, Final Submission by Federation of Australian Radio Broadcasters Limited to House of Representatives Standing Committee on Communications, Transport and the Arts Inquiry into the adequacy of regional radio, Report, 23 May.

Flew, T., 2000, 'Down by laws: commercial talkback radio and the ABA 'Cash for Comment' Inquiry,' Australian Screen Education, no. 24, pp. 10 - 15. 
Fitzgerald, R., and Housley, W., 2002, 'Identity, categorization and sequential organisation: the sequential and categorical flow of identity in a radio phone-in', Discourse \& Society, vol.13, iss.5, pp. $579-602$.

Griffen-Foley, B., 2004, 'From Tit-Bits to Big Brother: a century of audience participation in the media', Media, Culture \& Society, vol. 26, no. 4, pp. 533 548.

Higgins, C.S., and Moss, P.D., 1982, Sounds Real: Radio in everyday life, University of Queensland Press, Brisbane.

Hutchby, I., 1991, 'The Organization of Talk on Talk Radio', in (ed) P. Scannell, Broadcast Talk, Sage Publications, London, pp. 119 - 137.

Hutchby, I., 1996, "Power in discourse: the case of arguments on a British talk radio show", Discourse \& Society, vol. 7, iss. 4, pp. $481-497$.

Jefferson, G., and Lee, J., 1981, 'The Rejection of Advice: Managing the Problematic Convergence of a "Troubles-telling" and a "Service Encounter", Journal of Pragmatics, vol. 5, pp. 399 - 422.

Lewis, G., 1992, 'Talkback radio and John Laws', Stay Tuned: An Australian Broadcasting Reader, Allen \& Unwin, North Sydney, pp.85-89.

Mac, W., 2005, Don't Touch that Dial: Hits 'n' Memories of Australian Radio, WDJM, Canberra.

Mickler, S., 1997, 'The 'Robespierre of the air: talk-back radio, globalisation and Indigenous issues', Continuum, vol. 11, iss. 3, pp. 23 - 36. 
Ohara, Y., and Saft, S., 2003, 'Using conversation analysis to track gender ideologies in social interaction: toward a feminist analysis of a Japanese phone-in consultation TV program', Discourse \& Society, vol. 14, iss. 2, pp. 153 - 172.

Oktar, L., 2001, 'The ideological organisation of representational processes in the representation of us and them", Discourse \& Society, vol. 12, iss. 3, pp. $313-346$.

Osborne, G., and G. L., 2001, Communication Traditions in Australia, Oxford University Press, Melbourne.

O’Regan, M., 2003, ‘Tuning into Talkback', Media Report (Radio Program ABC) 25 September, URL: http://www.abc.net.au/rn/talks/8.30/mediarpt/stories/s951783.htm

O'Sullivan, S., 2005, 'The whole nation is listening to you': the presentation of the self on a tabloid talk radio show', Media, Culture \& Society, vol. 27, iss. 5, pp. 719738.

Page, B. I. and Tannenbaum, J. 1996, "Populistic deliberation and talk radio", Journal of Communication, vol. 46, iss. 2, pp. $33-55$.

Rendle-Short, J., 2005, 'I've got a paper-shuffler for a husband': indexing sexuality on talk-back radio', Discourse \& Society, vol. 16, iss 4, pp. $561-578$.

Shanahan, M., and Brown, N. 2002, 'Radio Listening as a Function of Basic Human Need: Why Did Maslow Listen To Radio?', Journal of Media Psychology, vol. 7, num. 3, Fall. URL: http://www.calstatela.edu/faculty/sfischo/maslow.html

Turner, G., 2000, 'Talkback, advertising and journalism: A cautionary tale of selfregulated commercial radio', International Journal of Cultural studies, vol. 3, iss. 2, pp. $247-255$. 
Turner, G., 2001, 'Ethics, Entertainment, and the Tabloid: the case of talkback radio in Australia', Continuum: Journal of Media and Cultural Studies, vol 15, No. 3. pp. $349-357$.

Ward, I., 2002, 'Talkback radio, political communication, and Australian politics', Australian Journal of Communication, vol. 29, iss. 1, pp. 21 - 38 . 